\title{
Characterization and Technological Properties of Bifidobacterium Strains Isolated from Breast-fed Infants
}

\author{
Bahloul Halima Auras, Hadadji Miloud, Guessas bettache, Saidi Noureddine and Kihal mebrouk \\ Laboratory of Applied Microbiology, Department of Biology, Faculty of Science, University of Oran El-menaouer, BP 1524, \\ Es-SeniaOran 31100, Algeria
}

Received: May 24, 2012 / Published: October 20, 2012.

\begin{abstract}
Bifidobacteria represent the largest group of human intestinal bacteria. They have an important place in human health and represent the dominant group microflora of the newborn breast-fed. Following the behavior of strains of Bifidobacteria isolated from the breast-fed infants and from saline rehydration solution was considered in order to develop therapeutic fermented milk. Samples from newborn infants aged 10 months, or from a saline rehydration solution (Celia/Develop ORS) containing Bifidobacteria sold was used and isolated strains belonged to breve and longum species. Those strains showed preferences to neutral $\mathrm{pH}$. They are mesophilic and tolerate high temperatures $\left(42^{\circ} \mathrm{C}\right)$. Glucose was commonly carbohydrate used in selective media for Bifidobacteria. Production of titratable acidity and therefore lowering the $\mathrm{pH}$ varies from one strain to another.
\end{abstract}

Key words: Ecology, Bifidobacterium, antibiotic resistance, kinetics of growth, acidity.

\section{Introduction}

Bifidobacteria form the largest group of human intestinal bacteria, especially in children [1]. They occupy an important place in human health. The first species of this genus isolated in 1899 from a healthy infant breast-fed by Henry Tissierwhich was classified later as Bifidobacterium bifidum. They settle in a short time after birth and become the dominant group of bacteria, $92 \%$ of the microflora of the newborn breast-fed consists of Bifidobacteria. However, the rate of these bacteria is reduced in favor of Lactobacilli, Enterobacteriaceae, Streptococci and Clostridia throughout life [2].

Some properties of Bifidobacteria have promoted their use in food products called probiotics [3] such as fermented milks, cheese and milk powder [4].

The effect of probiotic Bifidobacteria depends on their survival not only in food but also in the gastrointestinal tract [5]. For this reason, it becomes

Corresponding author: Hadadji Miloud, professor, research fields: food and applied microbiology. E-mail: hadadjimiloud@yahoo.fr. necessary to identify and assess the population of Bifidobacteria in fermented products to ensure a sufficient intake of probiotics for the expected benefits.

\section{Materials and Methods}

\subsection{Origin of Samples}

Samples were obtained from newborn infants aged 10 months, or from a saline rehydration solution (Celia/Develop ORS) containing Bifidobacteria sold, citrate, lactodextrane, sucrose, minerals, and traces of milk and banana aroma.

\subsection{Culture Media}

The isolation of Bifidobacteria was performed on MRS supplemented with $0.05 \%$ cysteine-chloride and $2 \mathrm{mg} / \mathrm{L}$ nalidixic acid at $\mathrm{pH}$ 6.8. Isolation requires strict anaerobic conditions (anaerobic jars with gas-packs).

The purification is performed by successive transplanting from Petri plates containing selective medium (MRS medium supplemented with 0.05\% cysteine-chloride and $2 \mathrm{mg} / \mathrm{L}$ nalidixic acid). For 
storage, the strains were frozen at $-20{ }^{\circ} \mathrm{C}$ in skim milk containing $30 \%$ glycerol, $10 \%$ of yeast extract and $0.2 \%$ cysteine- $\mathrm{HCl}$ [6].

\subsubsection{Biochemical and Physiological Testing}

The pre-identification begins with the observation of colonies on MRS medium supplemented with $0.05 \%$ cysteine-chloride and $2 \mathrm{mg} / \mathrm{L}$ nalidixic acid. A catalase test is carried out. Research the type fermentation, production of indole, citrate on middle Kempler and Mc Kay, the demonstration of urease are performed. The test of proteolysis of gelatin and by a growth test on bile which is an important criterion for the selection of probiotics was followed. The influence of $\mathrm{pH}$ was tested on strains selected at different $\mathrm{pH}(4,5,6.5,8.5$ and 8 ) and the influence of incubation temperature $\left(25^{\circ} \mathrm{C}, 30^{\circ} \mathrm{C}, 45^{\circ} \mathrm{C}\right.$ ) followed by a growth test in hyper saline environment at $4 \%, 6.5 \% \mathrm{NaCl}$.

\subsection{Fermentation of Carbohydrates}

The fermentation of sugar is examined on MRS medium containing bromocresol purple as $\mathrm{pH}$ indicator. $2 \%$ of various sugars (arabinose, glucose, fructose, galactose, lactose, maltose, mannitol, rhamnose, sucrose, xylose, esculin and sorbitol) are added. The preparations were covered with $1 \mathrm{~mL}$ of sterile paraffin oil for anaerobiosis. Incubation is carried out at $37{ }^{\circ} \mathrm{C}$ from 24 to $48 \mathrm{~h}$

The results of various tests morphological, physiological and biochemical are compared to those described by different authors [7].

\subsection{Antibiogram}

Antimicrobial susceptibility of Bifidobacteria strains is determined by the standardized technique of diffusion on MRS agar supplemented with $0.05 \%$ cysteine chloride and $2 \mathrm{mg} / \mathrm{L}$ nalidixic acid. The discs are tested: Amikacin, Amoxycillin + Clavulanic Acid, Ampicillin, Bacitracin, Cefazolin, Cefotaxime, Cefoxitin, cefsulodin, Ceftazidime, Cephalothin, Ciprofloxacin, Clindamycin, Colistin, Erythromycin, Fusidic Acid, Imipenem, Lincomycin, Nalidixic Acid, Netilmicin, Nitrofurantoin,
Ofloxacin, Oxacillin, pefloxacin, Penicillin, Piperacillin, Pristinamycin, Rifampin, Spiramycin, Erythromycin, Ticarcillin, Tobramycin, Trimethoprim-sulfamethoxazole (co-trimoxazole).

In parallel, an antibiotic reference strains Staphylococcusaureus ATCC 25923, Staphylococcusaureus 29213, Staphylococcusaureus ATCC 43300 is directed by the same technique on both media and Muller Hinton MRSV ancomycin. All discs from Bio-Rad (Marnes-la-Coquette, France), except Vancomycin of Oxoid (Basingstoke, Hampshire, England).

\subsection{Kinetics of Growth}

In pure culture, the kinetics growth of Bifidobacteria strains is followed by counting on MRS medium supplemented with $0.05 \%$ cysteine-chloride and 2 $\mathrm{mg} / \mathrm{L}$ nalidixic acid) solid, and at different time (0 h, 2 h, 4 h, 6 h ...up to 72 h).

\subsubsection{Determination of Titratable Acidity}

The determination of acidity during growth in milk was performed as described by Accolas et al. [8], using $\mathrm{NaOH}(\mathrm{N} / 9)$ in the presence of phenolphthalein indicator ( $1 \%$ in alcohol).

$\mathrm{pH}$ monitoring during the growth.

The acidity produced in the milk is also followed by measuring the $\mathrm{pH}$ using a $\mathrm{pH}$ meter.

\section{Results and Discussion}

The colonies of Bifidobacteria developed on MRS medium supplemented with $0.05 \%$ cysteine-chloride and $2 \mathrm{mg} / \mathrm{L}$ nalidixic acid are Gram positive appearance varies. They are whitish and cream, regular contour, and of varying diameter. This macroscopic appearance is often found in Bifidobacteria. The purified strains were all catalase negative, they do not possess urease, do not produce indole and do not liquefy gelatin but they are resistant to $2 \%$ of bile. These characteristics are typical of the genus Bifidobacterium. The results showed that all strains ferment some sugars (glucose, fructose, maltose and 
lactose). Strains BL1, BL2 ferment arabinose. This property seems to distinguish the species from other species longum. Moreover, strains BR1, BR2 do not ferment arabinose, xylose or the cons they ferment sorbitol, all these characterstics were schowed in Table 1.

With reference to the literature, the strains isolated from fecal of newborn infants belong to two species of Bifidobacterium. The two strains BL1 and BL2 belonged to the species longum and BR1 and BR2 (isolated from saline rehydration solution) to breve.

Table 1 Morphological, biochemical and physiological strain BR1, BL1 and BL2 isolated from the fecal newborn infants and BR2 strain isolated from the saline rehydration solution.

\begin{tabular}{|c|c|c|c|c|}
\hline \multirow{2}{*}{ Characterestics } & \multicolumn{4}{|c|}{ The strains } \\
\hline & BR1 & BR2 & BL1 & BL2 \\
\hline Macroscopic aspect & $\begin{array}{l}\text { Crean } \\
\text { regulc }\end{array}$ & $\begin{array}{l}\text { colonies, } \\
\text { r contour }\end{array}$ & $\begin{array}{l}\text { Punc } \\
\text { crean }\end{array}$ & $\begin{array}{l}\text { white and } \\
\text { lar contour }\end{array}$ \\
\hline Microscopic aspect & & Rods & Rods & $\begin{array}{l}\text { rmebifide } \\
\text { Y) }\end{array}$ \\
\hline Gram stainreaction & + & + & + & + \\
\hline Catalase & - & - & - & - \\
\hline Citrate permease & + & + & + & + \\
\hline Indole production & - & - & - & - \\
\hline Urease & - & - & - & - \\
\hline Gelatin Hydrolysis & - & - & - & - \\
\hline Bile resistance (2\%) & + & + & + & + \\
\hline $\mathrm{CO}_{2}$ & - & - & - & - \\
\hline Glucose & + & + & + & + \\
\hline Lactose & + & + & + & + \\
\hline Fructose & + & + & + & + \\
\hline Arabinose & - & - & + & + \\
\hline Xylose & - & - & $+/-$ & + \\
\hline Maltose & + & + & $+/-$ & + \\
\hline Mannitol & + & + & - & - \\
\hline Esculine & + & + & - & - \\
\hline Sucrose & + & + & + & + \\
\hline Rhamnose & - & - & - & - \\
\hline Sorbitol & + & $+/-$ & - & - \\
\hline Galactose & + & + & $+/-$ & $+/-$ \\
\hline $\mathrm{pH} 4,5,8.5$ & - & - & - & - \\
\hline $\mathrm{pH} 6.5,8$ & + & + & + & + \\
\hline $\mathrm{T} 4{ }^{\circ} \mathrm{C}, 5^{\circ} \mathrm{C}, 25^{\circ} \mathrm{C}$ & - & - & - & - \\
\hline $\mathrm{T} 45^{\circ} \mathrm{C}$ & - & + & - & - \\
\hline $\mathrm{NaCl} 4 \%$ & + & + & + & + \\
\hline $\mathrm{NaCl} 6.5 \%$ & - & - & - & - \\
\hline
\end{tabular}

The results of sensitivity or the resistance of the strains isolated from fecal or from saline rehydratation solution to the different antibiotics were regrouped in the Table 2. The growth kinetics results of the strains BL1, BL2, BR1 and BR2 in pure culture are illustratd in the Fig. 1A, the evolution of $\mathrm{pH}$ Fig. $1 \mathrm{~B}$ and titrableacidity Fig. 1C.

Bifidobacteria are commensal bacteria of humans, they are also found in animals [9]. The isolation of

Table 2 Susceptibility (sensitivity and resistance) strains BR1, BL1 and BL2 isolated from the fecal newborn infants and BR2 strain isolated from the saline rehydration solution.

\begin{tabular}{|c|c|c|c|c|c|c|}
\hline Antibiotics & $\begin{array}{l}\text { Charge of } \\
\text { discs }\end{array}$ & Symbol & BL1 & BL2 & BR1 & BR2 \\
\hline Amikacin & $30 \mu \mathrm{g}$ & AN & S & $\mathrm{R}$ & $\mathrm{R}$ & $\mathrm{R}$ \\
\hline $\begin{array}{l}\text { Amoxycillin } \\
\text { Clavulanic acid }\end{array}$ & $20 \mu \mathrm{g}+10 \mu \mathrm{g}$ & AMC & S & S & S & S \\
\hline Ampicillin & $10 \mu \mathrm{g}$ & $\mathrm{AM}$ & $\mathrm{R}$ & S & S & S \\
\hline Bacitracin & $20-40 \mu \mathrm{g}$ & BAC & & & & \\
\hline Cefazolin & $30 \mu \mathrm{g}$ & $\mathrm{CZ}$ & S & S & S & S \\
\hline Cefotaxime & $30 \mu \mathrm{g}$ & СТХ & S & $\mathrm{S}$ & $\mathrm{R}$ & S \\
\hline Cefoxitin & $30 \mu \mathrm{g}$ & FOX & S & $\mathrm{S}$ & S & S \\
\hline Cefsulodin & $30 \mu \mathrm{g}$ & CFS & $\mathrm{R}$ & $\mathrm{R}$ & $\mathrm{R}$ & $\mathrm{R}$ \\
\hline Ceftazidime & $30 \mu \mathrm{g}$ & CAZ & $\mathrm{R}$ & S & S & S \\
\hline Cephalothin & $30 \mu \mathrm{g}$ & $\mathrm{CF}$ & S & S & S & S \\
\hline Ciprofloxacin & $5 \mu \mathrm{g}$ & CIP & $\mathrm{R}$ & $\mathrm{R}$ & $\mathrm{R}$ & S \\
\hline Clindamycin & $2 \mu g$ & $\mathrm{CM}$ & S & $\mathrm{S}$ & $\mathrm{R}$ & S \\
\hline Colistin & $50 \mu \mathrm{g}$ & CS 50 & $\mathrm{R}$ & $\mathrm{R}$ & S & $\mathrm{R}$ \\
\hline Erythromycin & $15 \mu \mathrm{g}$ & $\mathrm{E}$ & $\mathrm{S}$ & S & $\mathrm{R}$ & S \\
\hline Imipenem & $10 \mu \mathrm{g}$ & IPM & S & $\mathrm{S}$ & S & S \\
\hline Lincomycin & $15 \mu \mathrm{g}$ & $\mathrm{L}$ & S & S & $\mathrm{R}$ & S \\
\hline Nalidixic Acid & $30 \mu \mathrm{g}$ & NA & $\mathrm{R}$ & $\mathrm{R}$ & S & $\mathrm{R}$ \\
\hline Netilmicin & $30 \mu \mathrm{g}$ & NET & $\mathrm{R}$ & S & S & S \\
\hline Nitrofurantoin & $300 \mu \mathrm{g}$ & FT & S & S & S & S \\
\hline Ofloxacin & $5 \mu \mathrm{g}$ & OFX & $\mathrm{R}$ & $\mathrm{R}$ & $\mathrm{R}$ & S \\
\hline Oxacillin & $1 \mu \mathrm{g}$ & OX1 & $\mathrm{R}$ & $\mathrm{R}$ & $\mathrm{R}$ & $\mathrm{R}$ \\
\hline Pefloxacin & $5 \mu \mathrm{g}$ & PEF & $\mathrm{R}$ & $\mathrm{R}$ & $\mathrm{R}$ & S \\
\hline Penicillin & $6 \mu \mathrm{g} / 10 \mathrm{IU}$ & $\mathrm{P}$ & S & S & $\mathrm{R}$ & S \\
\hline Piperacillin & $75 \mu \mathrm{g}$ & PIP 75 & S & S & S & S \\
\hline Pristinamycin & $15 \mu \mathrm{g}$ & $\mathrm{PT}$ & S & S & S & $\mathrm{S}$ \\
\hline Rifampin & $30 \mu \mathrm{g}$ & RA 30 & S & S & S & S \\
\hline Spiramycin & $100 \mu g$ & SP & S & S & $\mathrm{R}$ & S \\
\hline Tetracycline & $30 \mu \mathrm{g}$ & $\mathrm{TE}$ & S & S & S & S \\
\hline Ticarcillin & $75 \mu \mathrm{g}$ & TIC & S & S & $\mathrm{R}$ & S \\
\hline Tobramycin & $10 \mu \mathrm{g}$ & $\mathrm{TM}$ & $\mathrm{R}$ & $\mathrm{R}$ & $\mathrm{S}$ & $\mathrm{R}$ \\
\hline $\begin{array}{l}\text { Trimethoprim-su } \\
\text { lfamethoxazole } \\
\text { (co-trimoxazole) }\end{array}$ & $\begin{array}{l}1.25 \mu g \\
23.75 \mu g\end{array}$ & SXT & $\mathrm{R}$ & $\mathrm{R}$ & $\mathrm{R}$ & $\mathrm{R}$ \\
\hline Vancomycin & $30 \mu \mathrm{g}$ & VA & S & S & $\mathrm{S}$ & S \\
\hline
\end{tabular}




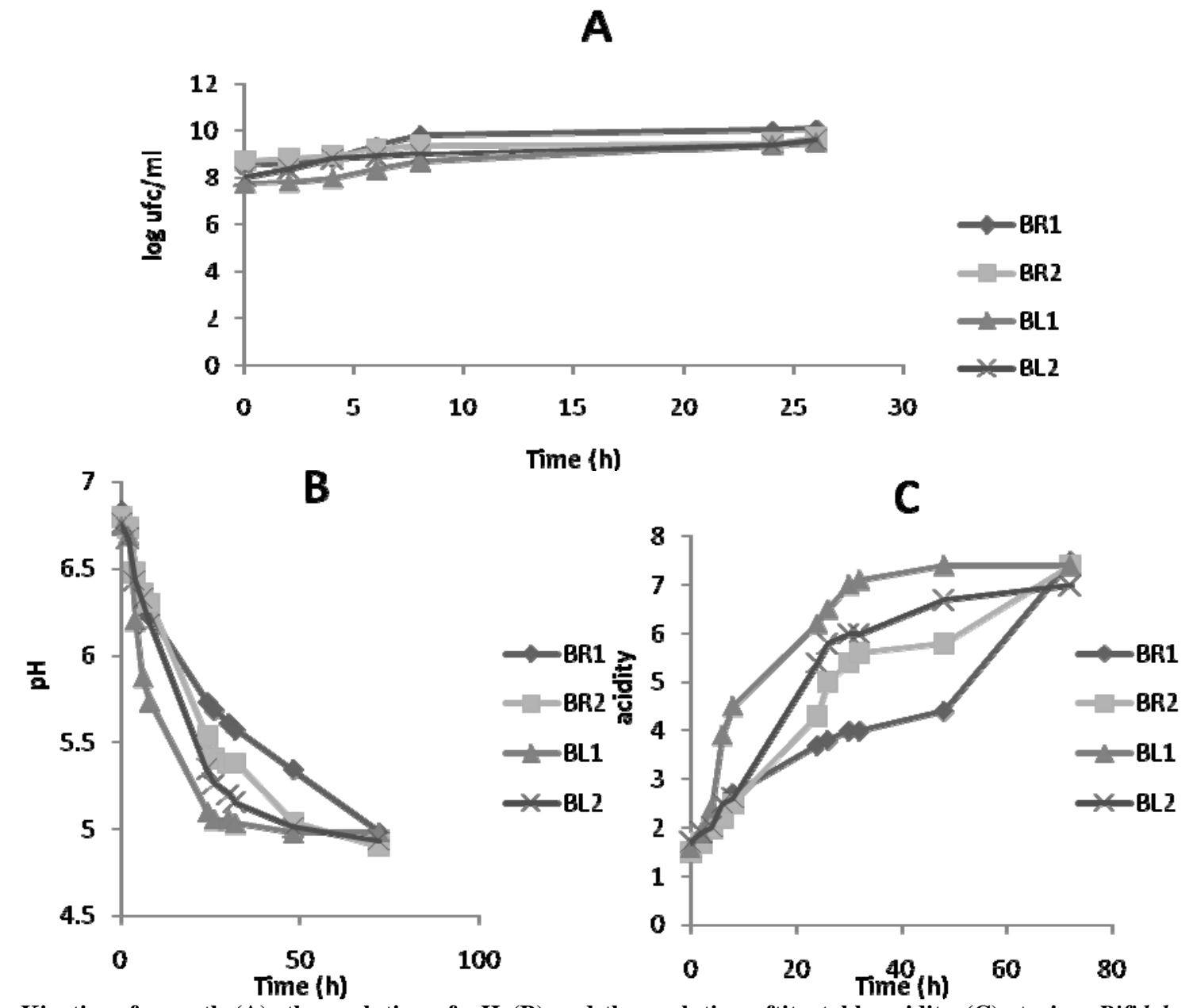

Fig. 1 Kinetics of growth (A), the evolution of $\mathrm{pH}(\mathrm{B})$ and the evolution oftitratable acidity (C) strains: Bifidobacterium longum BL1, BL2 and Bifidobacterium breve BR1, BR2 in skim milk medium without yeast extract.

Bifidobacteria requires quite specific conditions, which involve systems such as anaerobic Anaerocult or gas pack and rich culture media such as TPY, Beerens medium, MRS cysteine, Columbia medium modified [7, 10, 11]. The pre-identification of strains of bifidobacteria on MRS medium supplemented with 0.05\% cysteine chloride and $2 \mathrm{mg} / \mathrm{L}$ nalidixic acid showed an appearance of small colonies regular outline and variable aspect.

Cells forming colonies are Gram positive, characterized by varying forms, but often bifid forms that are typical for Bifidobacteria. Pleomorphism observed in Bifidobacteria is often associated with the composition of culture medium. Studies have shown that the cellular morphology of Bifidobacteria is influenced by the nature of the carbon source present in the culture medium $[2,13]$.

All strains belonging to the genus Bifidobacterium are catalase negative, which does not form indole, does not have a urease activity and does not liquefy gelatin. These biochemical characteristics are consistent with additional features specific to gender, reported by Mitsuoka [14].

All Bifidobacteria strains showed good growth on medium supplemented with $2 \%$ bile salts. Also it is found that the Bifidobacteria degrade bile salts, this criterion probiotic is due to an enzyme that hydrolyzes bile salts (BHS) [15], this enzyme was isolated from the stem Bifidobacterium longum BB536 [16], and in strain Bifidobacterium longum SBT2928 [17]. Adaptive mechanisms of tolerance to bile salts could lead to better adaptation to the environment and colonic 
available carbon sources and a persistent increase in the viability of Bifidobacterium in the intestinal environment [18, 19].

The strains isolated from fecal of newborn infants are resistant to nalidixic acid, trimethoprim-sulfamethoxazole (cotrimoxazole). These antibiotics are used as selective agents in synthetic media for the isolation and enumeration of Bifidobacteria [20]. Differentiation of Bifidobacterial species is based on the fermentation of carbohydrates. Indeed, Bifidobacterium longum NCC 2705 has genes coding for fumarase, oxoglutarate dehydrogenase in, and malate dehydrogenase. These enzymes allow the degradation of several sugars (arabinose, xylose, ribose, cellobiose, melibiose, maltose, raffinose and mannose) [21].

The comparison with the profile described by fermentation Scardovi [7] and Tamime et al. [22] led to identifying two species of Bifidobacterium breve which includes strains BR1, BR2, the species longum BL1, BL2.

The degradation of carbon substrates by Bifidobacteria leads to the formation of two acids (lactic and acetic) which lead to a lowering of $\mathrm{pH}$ of the medium. This shift in $\mathrm{pH}$ has no influence on the growth of these bacteria for 24 hours of incubation [23].

The effect of $\mathrm{pH}$ on microbial growth affects enzyme activity, cell permeability of certain nutrients which depends on ionic balance. The results showed that at $\mathrm{pH} 4,4.5$ and 5 no growth was observed. Bifidobacteria are generally sensitive to $\mathrm{pH}$ values below 4.6 [24]. Matsumoto et al. [25] indicated that tolerance of Bifidobacterium longum, Bifidobacterium adolescentis and Bifidobacterium pseudocatenulatum at acidic $\mathrm{pH}$ values is limited, a significant decrease in the viability of strains in a medium at $\mathrm{pH} 3$ after only one hour of incubation. Moderate growth and a significant slowdown in growth of the strains isolated from fecal and saline rehydration solution is obtained in the medium at $\mathrm{pH} 8$ and a total inhibition in the medium at $\mathrm{pH}$ 8.5. Optimum growth for different strains is obtained in the medium at $\mathrm{pH}$ 6.5.
These results confirm that Bifidobacteria prefering neutral or slightly acidic $\mathrm{pH}$ was between 5 and 8 as was reported by several authors [26-29].

The incubation temperature is on transport systems through the membrane and therefore the disruption of cellular metabolism. The results of the growth of Bifidobacterium strains in MRS medium cysteine, incubated at various temperatures show variability in behavior among species and strains. Indeed at incubation temperature of $4{ }^{\circ} \mathrm{C}$ and $25{ }^{\circ} \mathrm{C}$, there is complete inhibition of growth.

Moreover, the growth of all strains is better at the incubation temperature of $30{ }^{\circ} \mathrm{C}$ and $37{ }^{\circ} \mathrm{C}$. At a temperature of $45^{\circ} \mathrm{C}$, there is a total absence of growth of three strains of Bifidobacterium isolated from fecal newborn infants. This behavior can be explained by the fact that the strains are of human origin and cannot withstand high temperatures. The same results were reported by several authors [7, 9, 30, 31]. While there is moderate growth of the strain BR2 isolated from saline rehydration solution. These observations show firstly that the incubation temperature is an important parameter that can affect the growth of Bifidobacteria, which, on the other hand, confirms that Bifidobacteria of human origin are mesophilic bacteria growing at optimal temperatures of $30-37{ }^{\circ} \mathrm{C}$, but can adapt to higher temperatures.

If the introduction of Bifidobacteria in dairy industry has made there over 20 years in technologically advanced countries, it is against, not yet possible in some other countries such as Algeria. This situation is related to the constraints posed by the genus Bifidobacterium which is very sensitive to acidity developed in milk and aerobically on prevailing there.

Production of acidity depends on several parameters: incubation temperature, physiological state of bacteria, the inoculum concentration, and the milk used. Evaluation of titratable acidity, $\mathrm{pH}$ and the number of bacteria produced during growth of strains in pure culture as well reveal a significant difference between Bifidobacterium strains used (BL1, BL2, BR1, and 
BR2) of as much as Martinez-Villaluenga and Gomes [32] observed that the growth rate and generation time of bifidobacteria in the UHT milk vary among strains. After $6 \mathrm{~h}$ of incubation it is observed that the strains (BL1, BL2) belonging to Bifidobacteriumlongum are more acidifying than strains belonging to Bifidobacterium breve (BR1, BR2). Differences in acid production by strains of bifidobacteria have been reported by several authors [32-34]. These differences in behavior of Bifidobacterium strains in the different milks may be due partly to the composition of milk and also to the proteolytic activity that varies from strain to strain.

Survival of Bifidobacteria remains low. However, this survival may also be significantly improved by the addition of indigestible substances commonly known as "prebiotics". Among prebiotics mainly used in the food industry, there are inulin and oligofructose, honey bee [35]

On the other hand, another factor that appears to inhibit the growth of Bifidobacteria in milk medium is oxygen; however the degree of tolerance to this factor depends on the species and culture medium; to remedy this problem the adding a reducing agent such as cysteine hydrochloric seems to have its effect.

\section{Conclusions}

According to the results of the phenotypic characterization the strains (BL1, BL2, BR1 and BR2) were isolated from breast-fed infants and saline rehydratation solution belonged to two species of Bifidobacterium (longum, breve). The strains BL1 and BL2 have shown some technological properties such as the tolerance to the high temperature $\left(42^{\circ} \mathrm{C}\right)$, production of acidity, the resistance to the antibiotics and their kenitics of growth in skim milk, which suggests their possible use in the food industry. However, more studies are needed to test these strains for the human health.

\section{References}

[1] R. Barrangou, P. Briczinski, L. Traege, R. Loquasto, M.
Richards, P. Horvath, et al., Comparison of the complete genome sequences of Bifido bacterium animalis subsp. lactis DSM 10140 and Bl-04, Journal of Bacteriology 191 (2009) 4144-4151.

[2] F. Turoni, Bifidobacterial diversity in the human intestine, Appl. Environ. Microbiol. 75 (6) (2009) 1534-1545.

[3] P. Brigidi, B. Vitali, E. Swennen, L. Altomare, M. Rossi, Specific detection of Bifidobacterium strains in a pharmaceutical probiotic product and in human feces by polymerase chain reaction, Systematic Applied Microbiology 23 (2000) 391-399.

[4] D. Yann, Production en continu de ferments lactiques probiotiques par la techniques des cellules immobilisées, Thèse Présentée à la Faculté des études supérieures de l'Université Laval pour l'obtention du grade de Philosophiae Doctor, 2003.

[5] M. Gagnon, E. Kheadr, L.B. Gwenaelle, I. Fliss, In vitro inhibition of E. coli 0157:H7 by bifidobacterial strains of humain origin, Int. J. Food. Microbiol 92 (2004) 69-78.

[6] A.M.K. Frank, F. Kegma, H.A. Weerkamp, Growth and survival of bifidobacteria in milk, Neth. Milk. Dairy. J. 47 (1989) 151-164.

[7] V. Scardovi, Genus Bifidobacterium Orla Jensen, in: Bergey's Manual of systematic Bacteriology, IXe Edition, Williams, and Wilkins, Baltimore, 1986.

[8] J.P. Accolas, R. Bloquel, R. Didienne, J. Régnier, Propriétés acidifiantes des bactéries lactiques thermophiles en relation avec la fabrication du yoghourt, Lait 57 (1977) 1-23.

[9] B. Biavati, M. Vescovo, S. Torriani, V. Bottazzi, Bifidobacteria: History, ecology, physiology and applications, Annales of Microbiology 50 (2000) 117-131.

[10] J.F. Payne, A.E.J. Morris, P. Beers, Evolution of selective media for the enumiration of Bifidobacterium sp. in milk, Journal of Applied Microbiology 86 (1999) 353-355.

[11] M. Hadadji, R. Benaama, N. Saidi, D.E. Henni, M. Kihal, Identification of cultivable Bifidobacterium species isolated from breast-fed infants feces in west-Algeria, African Journal of Biotechnology 4 (5) (2005) 422-430.

[12] B. Biavatiand, P. Mattarelli, The family bifidobacteriaceae the prokaryotes, in: M. Dworkin, S. Falkow, E. Rosemberg, K.H. Shleifer, E. Stackbrandt (Eds.), Spiringer New York, 2001, pp. 1-70.

[13] E. Vlkova, J. Nevoral, B. Jencikova, J. Kopecny, J. Godefrooij, A. Trojanovai, et al., Detection of infant faecal bifidobacteria by enzymatic methods, Journal of Microbiological Methods 60 (2005) 365-373.

[14] T. Mitsuoka, Microbes in the Intestine, Yakult Honsha Co., Std Tokyo, 1989, p. 104.

[15] K. Pattel, R. Singhania, A. Pendey, B. Chincholkar, Probiotic Bile Salt Hydrolase:Current Development and Perspectives, Appel Biochem Biothecnol, 2009, DOI: 
10.1007/s12010-009-8738-1.

[16] J.P. Grill, J. Crociani, J. Ballongue, Caracteriszation of fructose 6-phosphate phosphoketolase purified from Bifidobacterium species, Current Microbiology 31 (1995) 49-54.

[17] H. Tanaka, H. Hashiba, J. Kock, Bile salt hydrolase of Bifidobacterium longum, biochimical and genetic characterisation, Appl. Env. Microbiology 66 (2000) 2502-2512.

[18] C.G. De los Reyes-Gavillan, P. Ruas-Madiedo, L. Noriega, I. Cuevas, B. Sanchez, A. Margolles, Effect of acqueredresistante to bil salts on enzymatic activities involved in the utilization of carbohydrates by Bifidobacteria, Lait 85 (2005) 113-123.

[19] M. Gueimonde, M. Margolles, G. Clara, De los Reyes-Gaavilan, S. Salminen, Competitive exclusion of enteropathogens from human intestinal mucus by Bifidobacterium strains with aquired resistance to a priliminary study, Int. J. Food Microbiology 113 (2007) 228-232.

[20] M. Ventura, D. Van-Sendiren, G.F. Fitzgerald, R. Zink, Insights into the taxonomy, genetics and physiology of Bifidobacteria, Antony Van Leevenhook 86 (2004) 205-223.

[21] M. Schell, M. Karmirantzou, B. Snel, D. Vilanova, B. Berger, G. Pessi, et al., The genom sequence of Bifidobacteriumlongum reflects its adaptation to the human gastrointestinal tract, Procnatlacadsciusa 99 (2002) 14422-14427.

[22] A.Y. Tamime, V.M.E. Marshall, R.K. Robinson, Microbiological and technological aspects of milks fermented by bifidobacteria, J. Dairy. Res. 62 (1995) 151-187.

[23] R.J. Palframan, G.R. Gibson, R.A. Rastall, Carbohydrates references of Bifidobacterium species isolated from human gut, Current Issues Intestinal Microbiological 4 (2003) 71-75.

[24] T.D. Boylston, C.G. Vinderola, H.B. Ghoddusi, J.A. Reinheimer, Incorporation of bifidobacteria into cheeses challenges and rewards, International Dairy Journal 14 (2004) 375-387.

[25] M. Matsumoto, H. Ohishi, Y. Hand Benno, $\mathrm{H}^{+}$-ATPase activity in Bifidobacterium with special reference to acid tolerance, Int. J. Food. Microbiol. 93 (2004) 109-113.

[26] M.B. Romond, C. Romond, D. Izard, Les groupes microbiens d'intérêt laitiers, in: J. Hermier, J. Lenoir, F. Weber (Eds.), Tec et Doc. Paris, 1992, pp. 61-80.

[27] A.S. Akalin, S. Fenderya, N. Akbulut, Viability and activity of bifidobacteria in yoghurt containing fructooligosaccharides during refrigerated storage, International Journal of Food Science 39 (2004) 613-621.

[28] M.C. Collado, Y. Moreno, J.M. Cobo, M. Hernandez, Microbiological evaluation and molecular characterization of bifidobacteria strains in commercial fermented milks, Europeen Food Reseach Technological 222 (2006) 112-117.

[29] L. Waddington, T. Cyr, M. Hefford, L.T. Hansen, M. Kalmokoff, Understanding the acid tolerance response of bifidobacteria, Journal of Applied Microbiology 108 (2010) 1408-1420.

[30] X. Dong, Y. Xin, W. Jian, X. Liu, D. Ling, Bifidobacterium thermacido philium sp. nov, isolated from anaerobic digester, Int. J. Syst. Evol. Microbiol. 50 (2000) 119-125.

[31] D. Szwajgier, K. Dmowska, Novel ferulic acid esterases from Bifidobacterium sp. produced on selected synthetic and natural carbon sources, Acta. Sci. Pol. Technol. Aliment. 9 (3) (2010) 305-318.

[32] C. Martinez-Villaluenga, R. Gomes, Characterization of Bifidobacteria as starters in fermented milk containing raffinose family of oligosaccharides from lupin as probiotic, Int. Dairy. J. 17 (2007) 116-122.

[33] R.G. Crittenden, L.F. Morris, M.L. Harvey, L.T. Tran, H.L. Mitchell, M.J. Playne, Selection of Bifidobacterium strain to complement resistant starch in symbiotic yoghurt, J. Appl. Microbiol. 90 (2001) 268-278.

[34] M. Hadadji, Caractérisation technologique des bifidobactériues à intérêt thérapeutique thèse de doctorat d'état, Université d’Oran, Algérie, 2007, p. 173.

[35] A. Riazi, H. Ziar, Croissance et viabilité des Bifidobactéries dans le lait écrémé additionnéde miel d'abeille, Nature et Technologie, 2010, pp. 17-24. 